\title{
Identity-Based Motivation: Implications for Health and Health Disparities
}

\author{
Daphna Oyserman* \\ University of Southern California
}

\section{George C. Smith and Kristen Elmore}

University of Michigan

People aspire to be healthy but often fall short of this goal. Poor health is associated with macro-level factors-social stratification and low socioeconomic position, including low education, low income, and low status racial-ethnic group membership. These social determinants differentially expose people to health-promoting (or undermining) contexts and to having (not having) choice and control over their lives. But social determinants cannot cause individual action directly. Identitybased motivation theory addresses this gap, articulating how social determinants operate at the micro-level to influence whether or not a behavior or choice feels congruent with important identities and how such identity-congruence, in turn, influences which strategies are chosen and how difficulty is interpreted. Lack of choice and control make an interpretation of difficulty as meaning that effort is pointless and "not for people like me" (rather than important) more likely, reducing belief that one's action and effort matter.

Americans aspire to be healthy and want to model healthy behavior for their children, but they often fall short of this goal, picking unhealthy options when they eat out and accumulating rather than losing excess weight (American Public Health Association, 2010; Associated Press, 2011; Gallop, 2010). One possible reason forthis aspiration-attainment gap is that healthy choices are personal choices that are hard to make and sustain (e.g., Brownell et al., 2010; Glanz, Rimer, \& Viswanath, 2008). Another possibility is that it is not difficulty itself, but what

\footnotetext{
* Correspondence concerning this article should be addressed to Daphna Oyserman, Department of Psychology, University of Southern California, Los Angeles, CA 90071. Tel: 213-740-2219 [e-mail: oyserman@usc.edu].

With thanks for funding support from the Alexander von Humboldt Foundation (Germany) to Oyserman, the National Science Foundation (Smith), and the Rackham Graduate Program (Elmore).
} 
difficulty is interpreted to mean for people like oneself, that matters. Supporting this latter possibility, ill health is unevenly distributed across racial-ethnic and social class groups (e.g., Adler \& Rehkopf, 2008; Alegría et al., 2011; Schnittker \& McLeod, 2005; Ybarra, Sanchez, \& Medeiros, 2011) and these same groups also report feeling disrespected, devalued, and discriminated against in health settings (for a review, see Alegría et al., 2011; Bird \& Bogart, 2001; Williams et al., 2012).

In the current article, we examine the psychological underpinnings influencing individual action in the context of social disparities. To do so, we start with a review of the relevant survey-based health and health disparities research and use identity-based motivation (IBM) theory (Oyserman, 2007, 2009a, b, in press) to frame how associations between health and social structure might occur. Because page limits do not allow an exhaustive review of all research on health disparities, we focus on recent survey-based empirical papers and reviews, emphasizing data from representative samples. Because survey data cannot provide causal explanations, we then focus on experimental tests of our causal predictions, complementing experimental evidence with illustrative ethnographic and interview data where experimental evidence does not yet exist but relevant health-related ethnographic or interview data do. Throughout we include examples from other countries but focus mainly on the United States. We show that people's health-related choices are identity-based, resulting in choices that do not always benefit them and may even undermine their health and well-being when more healthy choices do not feel identitycongruent.

We organize the article using the three core components of IBM theory: dynamic construction, action and procedural readiness, and interpretation of difficulty. For clarity, each component is described in a separate section. We start by providing an overview of the evidence for health disparities and the interface between these macro-level associations and processes at the individual level. Then we outline what is meant by dynamic construction of identity, highlighting identities likely to matter for engagement with health and beginning with a brief operationalization of what we mean by identity as an aspect of the self (a full discussion is beyond the purview of this article, for detailed discussion, see Oyserman, 2007, 2009a; Oyserman \& Destin, 2010; Oyserman, Elmore, \& Smith, 2012). Then, we link the second and third components of the IBM model (readiness to act and make meaning, and the interpretation of difficulty) to health and health disparities. We conclude by outlining implications of IBM for future research, policy, and interventions that address health and health disparities, highlighting how subtle shifts in context can set in motion important changes in health outcomes. We assume an American political lens while discussing implications, and focus on both racial-ethnic and social stratification issues more generally. 


\section{Health Disparities}

For poor health outcomes to constitute health disparities, it is necessary to see clustering of outcomes along social stratification lines. For example, consider obesity and smoking. Both seem to result from individual choices but individual choice alone cannot be the full explanation because both are differentially likely for people of varying social positions in society. Obesity and smoking cessation cluster by friendship and family ties (Christakis \& Fowler, 2007, 2008). These ties, in turn, tend to cluster within socioeconomic and racial-ethnic groups (Tamburlini \& Cattaneo, 2007). Moreover, once heavy weight people (or smokers) are part of one's in-group, weight (and smoking) may no longer be as salient. Thus, people are less likely to see a particular weight as problematic if they compare themselves to others who are heavier rather than thinner than themselves (Knecht, Reinholz, \& Kenning, 2007). As we will argue throughout this article, interventions that focus on this macro-micro interface and emphasize the meaning people make of their health possibilities can help in spite of the constraints imposed by social-structural variables.

While our example focused on obesity and smoking in the United States, health outcomes are socially stratified worldwide. Compared to people with high socioeconomic position, those with low socioeconomic position have worse health no matter if position is operationalized as (having or lacking) education, income, assets, employment, occupational prestige, racial-ethnic minority status, segregation, or social isolation (Adler \& Rehkopf, 2008; Williams \& Jackson, 2005). In longitudinal analyses, poorer health outcomes are found for individuals who have low socioeconomic position (Banks, Marmot, Oldfield, \& Smith, 2006), live in a socially stratified society (Banks et al., 2006), are socially isolated (House, Landis, \& Umberson, 1988), and lack social relationships (House et al., 1988). Socioeconomic position is also associated with worse health via its impact on the likelihood of unemployment, work-related choice and control (Adler \& Rehkopf, 2008), job insecurity (Burgard, Brand, \& House, 2009), vacillation in work hours with economic up and downswings (Ruhm, 2005), and higher rates of unfair treatment at work (Williams et al., 2012). Each of these factors is itself related to worse health.

Social stratification (low income, minority status) also predicts unfair treatment in medical settings. Thus compared to White Americans, Black Americans are more likely to feel disrespected, devalued, and discriminated against when interacting with physicians (Alegría et al., 2011; Bird \& Bogart, 2001; Williams et al., 2012). Over time, these feelings of unfair treatment and discrimination are associated with less follow-up with treatment, lower adherence to physician recommendations, and subsequent worse health for African American patients (Alegria et al., 2011; Bird \& Bogart, 2001; Penner et al., 2009). Corroborating their feelings of unfair treatment, low income and minority individuals are 
indeed more likely to be provided simple as opposed to maximally effective treatment regimens and in some cases are less likely to be offered health screening (e.g., Alegría et al., 2011).

Racial-ethnic group status and lower socioeconomic position are also associated with components of worse health-less physical activity, more smoking, and higher levels of obesity, hypertension, diabetes, and physical limitations during midlife (Banks, Marmot, Oldfield, \& Smith, 2006; Lantz et al., 1998; Link, Phelan, Miech, \& Westin, 2008; Lynch, Smith, Kaplan, \& House, 2000; Marmot, 2001). ${ }^{1}$ Again, consider smoking. While less than a quarter of Americans overall report that they smoke tobacco, almost half of African Americans living in inner city neighborhoods smoke. Moreover, when they smoke, they are likely to smoke a particular type of cigarette (menthol cigarettes) in a certain way (within $10 \mathrm{~min}$ utes of waking up) (Ahluwalia, Harris, Catley, Okuyemi, \& Mayo, 2002; Royce, Hymowitz, Corbett, Hartwell, \& Orlandi, 1993).

Although survey data cannot illuminate underlying causal processes, these similarities suggest not only a convergent propensity to smoke, but a propensity to smoke in a certain way (which unfortunately also increases health risk). One possibility is that position, stratification, segregation, and isolation each reduce control and agency which undermine healthy choices unless other supports are added (House et al., 1988). Indeed, support from church members and healthy lifestyle are positively associated for elderly Black congregants who are highly connected with their congregation and with unhealthy life style choices for elderly Black congregants who are less connected with their congregation (Krause, Shaw, \& Liang, 2011). Healthy lifestyle and church member support are not associated for elderly White congregants. Similarly, Black and White Americans who smoke tobacco, drink alcohol, and are heavy weight (obese) have more chronic health conditions but smoking, drinking, and heavy weight reduce risk of depression for Black (not White) Americans again suggesting a unique underlying process for socially marginalized groups (Jackson, Knight, \& Rafferty, 2010).

While reported data from survey research do not allow for more complex analyses of how this interface works, IBM theory predicts that race and socioeconomic position matter in part by influencing situational cues that make healthy or health-risky behaviors feel identity-congruent. The effects of stratified, segregated, and lower socioeconomic contexts are twofold. First, these contexts may cue relational or collectivistic mindsets; making social identities including raceethnicity come to mind. Second, in these contexts, such social identities are less likely to be associated with control, agency, and health. The next sections detail each of these constructs and predictions.

${ }^{1}$ Effects are strongest for English-speaking minorities (August \& Sorkin, 2010). 


\section{Identity-Based Motivation: Making Sense of the Macro-Micro Interface}

To begin to better understand how these macro-level factors interface with micro-level choices, we turn to IBM theory (Oyserman, 2007, 2009a, b). A number of perspectives propose that healthy behaviors may be identity-linked (e.g., Amos et al., 1997, 1998; Berger \& Rand, 2008; Bowen, Christensen, Powers, Graves, \& Anderson, 1998; Bowen, Hickman, \& Powers, 1997; Gibbons \& Gerrard, 1995, 1997; Gibbons, Gerrard, Blanton, \& Russell, 1998; Gray, Amos, \& Currie, 1997; Guendelman, Cheryan, \& Monin, 2011; Stead, McDermott, MacKintosh, \& Adamson 2011). IBM theory provides a specific set of predictions about how and when identity matters. IBM is a general model rooted in a situated-cognition perspective that was developed to understand motivational processes underlying the health, well-being, and academic choices (and outcomes) of individuals who are racial-ethnic minorities and are situated in low socioeconomic positions in society (Oyserman, 2008; Oyserman, Brickman, Bybee, \& Celious, 2006; Oyserman, Bybee, \& Terry, 2006; Oyserman, Fryberg, \& Yoder, 2012).

IBM theory predicts that people prefer to act in ways that fit their important identities, including racial-ethnic, gender, and social class-based identities, but that while these identities feel stable, they are highly situation sensitive. That is, identities are dynamically constructed and, while salient identities cue readiness to act and make meaning in identity-congruent ways, what an identity means and therefore which strategies, scripts, or norms are associated with it are also highly malleable. Figure 1 provides a simplified process model of the macromicro interface involved in IBM. In the first panel are factors associated with health disparities. These factors include race-ethnicity and social stratification more generally and are relevant to IBM because they both increase the likelihood that some identities (and not others) come to mind and frame what these identities are likely to mean in the moment. Accessible identities and the meaning ascribed to them cue readiness to act, are the meaning-making lens through which others are understood, and provide an interpretation of difficulty in thinking about and engaging in health-relevant action. These identity-based processes are predictive of action (physical activity, smoking, and diet), engagement with and interpretation of interactions with health-care providers, and interpretation of stress as threat or challenge.

\section{Identity-Based Motivation: Dynamic Construction of Identity}

Identities are nested in self-concepts, which make up part of the self's reflexive capacity to think, to be aware of one's thinking, and to take oneself as the object of thinking. Depending on the context, people are likely to structure the task of taking the self as the object of thinking differently. These structural differences are 


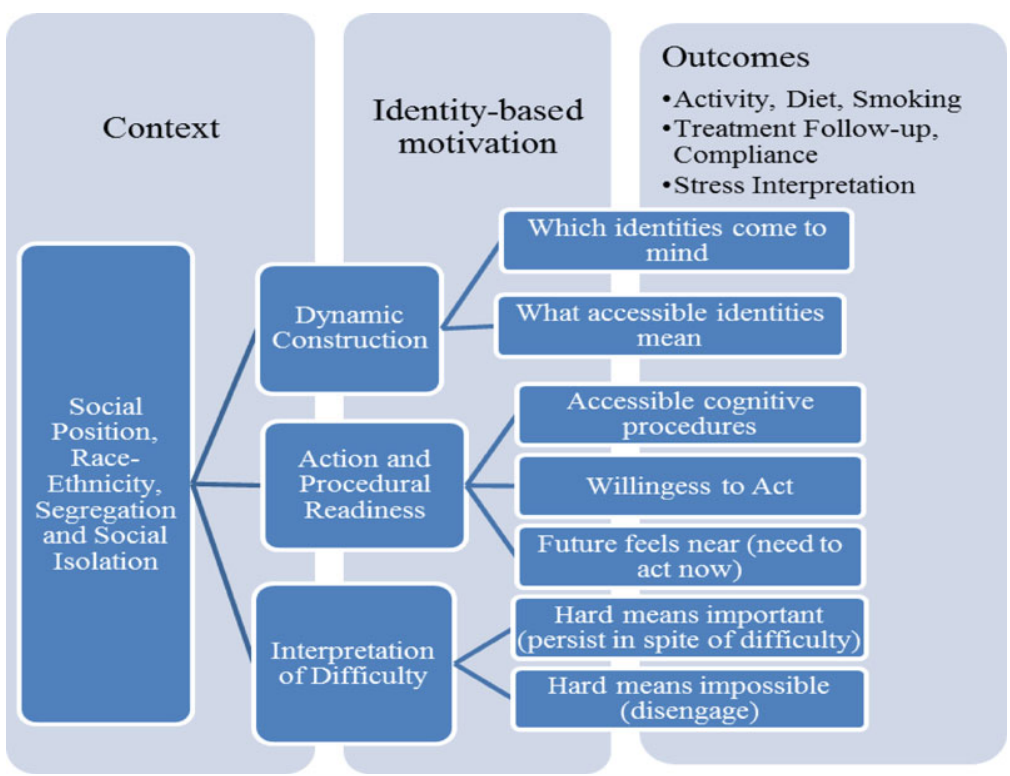

Fig. 1. How social contexts effect health outcomes is importantly influenced by the three components of identity-based motivation.

termed individualistic, relational, and collectivistic self-concepts (or mindsets) by cultural psychologists and social identity theorists (for more detailed review and discussion, see Oyserman, 2011; Oyserman, Elmore, \& Smith, 2012).

While often studied cross-culturally, a large body of evidence demonstrates that even subtle situational cues are sufficient to make an individualistic, relational, or collectivistic mindset accessible with consequences for identity content, cognitive procedures, and action. For example, just reading a paragraph and circling first person singular versus plural pronouns or considering the ways one is similar versus different to family and friends is enough to shift mindsets (see Oyserman, 2011; Oyserman et al., 2012). After circling "I," an accessible individualistic mindset brings personal identities (traits and characteristics) to mind. After circling "we," an accessible relational or collectivistic mindset brings social roles, relationships, and social group identities, including gender, race-ethnicity, and social class identities to mind (for a meta-analytic review, see Oyserman \& Lee, 2008).

These studies show that small shifts in the situation influence whether people think of themselves as members of their racial-ethnic group or as individuals with unique skills. Not only that, but these effects are automatic and do not require that people make a conscious choice as to how to think about themselves. In the 
next sections, we will use IBM theory to demonstrate that how one thinks about oneself (as an individual, as a group member) also influences which goals and strategies and which interpretation of difficulties in goal attainment come to mind in the domain of health.

\section{Dynamic Construction of Health-Relevant Identities}

\section{Experimental Evidence}

Oyserman, Fryberg, and Yoder (2012) conducted a series of seven experiments to test the dynamic construction of health-relevant identity predictions emanating from IBM theory. As detailed next, the first set of experiments supports the predicted link between health and identity. The second set of experiments supports the prediction that this link is moderated by momentarily accessible identity content.

In the initial study, participants were given a short questionnaire that asked them to fill in how often in the past week they had engaged in a list of healthy and less healthy behaviors. On the reverse side of the page, they were asked to rate how "White and middle class" these behaviors were. American Indian, African American, and Mexican American participants reported engaging in fewer healthy behaviors than White middle class participants. Minority participants also believed that White middle class people took better care of their health than they did, rating the healthy behaviors as "White and middle class," though actual White and middle class participants did not make the same connection (Oyserman et al., 2012, Study 1).

The next study used the same list of healthy and unhealthy behaviors. Instead of asking how "White and middle class" the behaviors were, minority participants were asked how much these behaviors were in-group defining. They believed that these behaviors (e.g., adding salt, eating fried foods, drinking soda, and smoking) were in-group defining and healthy ones (e.g., watching one's weight, eating salads, and exercising) were not (Oyserman et al., 2012, Study 2). A reader might interpret these findings that behaviors associated with health disparities are seen as racial identity-congruent to imply that there is not much that can be done to avoid these outcomes. However, IBM theory predicts that what is in-group defining is malleable and can be dynamically constructed in context.

Therefore, five experiments were conducted to test the prediction that unhealthy choices become more accessible depending on how racial-ethnic group membership is primed (brought to mind in context) (Oyserman et al., 2012, Studies 3-7). Low-income African American, Latino, and multiracial middle school students were randomly assigned to one of two conditions. In the control condition, participants were simply asked to report on their health knowledge (using material 
from their curriculum) or to report on their health fatalism beliefs (e.g., "Some people are healthy, others die young, that is just the way it is," "Everyone gets fat over time; there is no point worrying about it,"). In the experimental condition, they were subtly primed to consider these questions in the context of a salient racialethnic or social class identity by having them first respond to two question stems. First, participants responded to the stem "I am ..." by selecting a box containing one of the following race ethnicities: Black/African American, White/European American, or Hispanic/Mexican American/Latino. Then they read "In my family, having enough money" and the choices: "is an issue all the time," "is an issue some months more than others," "is an issue when I make plans." Students were more fatalistic about their health (Study 3) and less accurate in their health responses (Study 4) when their racial-ethnic and social class identities were first brought to mind.

Studies then tested how the context in which racial-ethnic identity was brought to mind moderated this effect. African American (Oyserman et al., 2012, Study 5) and American Indian (Oyserman et al., 2012, Studies 67) participants were randomly assigned to one of three conditions. In one condition, context set up a subtle contrast between African Americans and middle class White Americans. In another condition, similarities between African Americans and middle class White Americans were cued. In the third (control) condition, participants were not asked to compare their group with middle class White Americans at all. Then, all participants were asked how much a list of healthy activities (i.e., eating health foods, regular exercise, avoiding lots of sugar and fatty foods) mattered for health and longevity. Participants believed these behaviors important for health and longevity. However, if first led to contrast themselves to middle class White Americans, participants were less likely to see healthy behaviors as helpful.

To ensure that effects were neither demand-ridden nor based on explicit norms, in both of the experimental conditions participants were simply asked to list similarities between their own group and middle class White Americans. The difference between conditions was that in one condition, participants were asked to list a few similarities and in the other condition they were asked to list many similarities. Listing a few similarities was easy and convinced participants that they were similar to White Americans. In contrast, listing many similarities was difficult and even though participants were able to do it, experienced difficulty convinced participants that they were not similar to White Americans (see Schwarz et al., 1991, for a thorough review of this manipulation technique). Momentary similarity resulted in healthy behavior feeling identity-congruent; momentary difference resulted in healthy behavior feeling identity-incongruent. In each case, effects did not require explicit awareness or conscious reflection. This parallels what is likely to occur in real-world settings in which race-ethnicity or other social stratification variables are salient. 
That health-relevant identities can be dynamically constructed was also shown in a study with British college students. Students were more likely to plan for a healthy reduction of alcohol and salt intake when their British identity rather than their student identity was accessible at the moment of judgment. Thus, rather than shift how a particular identity was linked to healthy behaviors, this study demonstrates that people can use a variety of identities to think about the relevance of healthy behaviors (Tarrant \& Butler, 2011).

\section{Ethnographic Evidence}

A number of ethnographic studies provide supporting evidence for the IBM prediction that unhealthy choices may feel identity-congruent. American (Croghan, Griffin, Hunter, \& Phoenix, 2006) and British (Stead, McDermott, MacKintosh, \& Adamson 2011) low-income youth in focus groups report seeing their unhealthy food choices (including brands and types) as a way to affirm their identities. While data such as these and the Tarrant and Butler (2011) study described in the prior section may imply that identity effects are fixed and due to explicit norms, which identities come to mind and what they mean for healthy choices are clearly malleable as predicted by IBM and shown by the Oyserman, Fryberg, and Yoder (2012) experiments.

\section{Identity-Based Motivation: Implications for Action and Procedural Readiness}

In this section, we provide evidence that situationally cued identities carry with them readiness to act and make sense of the world in identity-congruent ways with health-promoting or health-undermining consequences depending on situational cues that are not necessarily consciously processed. These cues can come from the way that health is socially represented, labeled, and discussed in public discourse. For example, Smith and Robertson (2008) argue that "men's health" is often seen as separate and distinct from "women's health," and that "men's health" focuses more narrowly on athleticism while "women's health" focuses more broadly on healthy diet and exercise. Others have argued that "women's health" is commonly understood as health care related to sexuality and child-bearing to the exclusion of nonheterosexual and childless women, who often fail to attain health care.

Cues can also come from subtle differences in identity labels. Thus, in one study, African American women who self-identified as "African American" were more likely to seek mammography screening than those who self-identified as "Black," though the women did not differ in how worried they were that they might get breast cancer (Bowen, Hickman, \& Powers, 1997). A follow-up study provided group counseling for mammography (Bowen, Christensen, Powers, Graves, \& Anderson, 1998). The effect of group counseling was moderated by 
identity; women who described themselves as Black were less likely to obtain screening than those who described themselves as African American. While not directly tested, the authors infer that the "American" element of the African American identity was promotive of trusting the health system.

Cues can also come from subtle differences in what the same identity means in context as shown in an experiment conducted with Asian American college students. In the experimental condition, participants' were first asked if they spoke English or were American, calling the American part of their identity into question. Respondents in this condition chose more American than Asian foods, making higher calorie choices. In the control condition, participants "Americanness" was not called into question, and these participants selected more Asian foods than American foods, making healthier choices (Guendelman, Cheryan, \& Monin, 2011).

These studies imply that to successfully engage individuals in health promotion, it is not enough to provide health information. Rather, it is important that engaging in healthy behavior feel identity-congruent. Helweg-Larsen and Collins (1997) make this argument for HIV/AIDS prevention work as do studies describing ways to increase physical activity among individuals who might view exercise as something that is White, middle class, and not for people like them (Choudhry, 1992; Cooper, Hill, \& Powe, 2002; Martin \& Leary, 2001; Werch, 2007). The same is true for substance use interventions; linking valued possible identities to abstinence led to reduced alcohol and marijuana use (Werch et al., 2008) and reduced alcohol use at 3-month follow-up (Werch et al., 2005).

Although health disparities research often focuses explicitly on the negative consequences of IBM for the choices and behaviors of racial-ethnic minority and low socioeconomic status groups, IBM is a general theory which applies equally to nonminority and high status groups. Indeed, as shown in the studies reviewed next, identity-based consumption choices are not confined to low-income or minority groups. Effects may be health undermining or health bolstering as these studies show.

Take for example, the identity of an undergraduate. For many, being an undergraduate means engaging in a set of behaviors (e.g., pulling "all-nighters," consuming junk food, excessively consuming alcohol, using tobacco or marijuana) that together result in unintended poor health outcomes such as increased weight gain, depression, and accident risk (Werch et al., 2008). Weight gain in the first year of college is so common that it has a name, "the freshman fifteen." Gaining weight is not viewed positively, but the behavior which produces it is identity-congruent among individuals for whom being a college student is an important social identity.

But what an undergraduate identity means is dynamically constructed in context, as demonstrated in two studies by Berger and Rand (2008), who 
provided undergraduates with subtle cues about what others (graduate students) do and showed that undergraduates contrast themselves to graduate students. After learning that (nerdy) graduate students eat junk food, undergraduates chose fewer brownies and more apples in a shopping simulation. They reported less alcohol consumption after being exposed to posters against drinking which pointed out that lots of graduate students drink alcohol and the unpleasantness of being mistaken for a graduate student (as compared to students exposed to control posters about underage drinking, Berger \& Rand, 2008).

A variety of identities have been situationally linked to health. In one study, Cancer Research UK (cancer awareness) leaflets were more convincing to British students who were first led to consider their identity as cautious and preventionfocused than otherwise (Uskul, Keller, \& Oyserman, 2008). Other identities that have been associated with health-relevant behaviors include weight (McFerran et al., 2009), dieter (Irmak, Vallen, \& Robinson, 2011; McFerran et al., 2010) and even a "Green" environmentalist identity (Schuldt \& Schwarz, 2010).

Across studies, accessible identities influence judgment and behavior. What an accessible identity means for health is a dynamic construction evoked by the specific situation one finds oneself in. Contexts influence which identities come to mind and what these identities are taken to mean; this dynamically created identity carries with it judgments and behaviors that may be health-promoting or health-undermining, depending on what is afforded by the situational cues. In the next section, we consider IBM and the interpretation of difficulty.

\section{Identity-Based Motivation: Implications for Interpretation of Difficulty}

IBM theory predicts that people prefer to act in identity-congruent ways, but that the effect of identity can be difficult to see because what an identity means, which strategies feel congruent with that identity, and how difficulties along the way are interpreted are dynamically created in context (Oyserman, 2007, 2009a, b; Oyserman et al., 2012). Thus, IBM focuses on the need to interpret experienced difficulty working on one's future identities and not just on the positive power of having future identities. IBM theory posits that working on any important future identity, including becoming healthy, is difficult, but how experienced difficulty affects motivation depends on how it is understood. Specifically, motivation increases with experienced difficulty if difficulty is understood as meaning that the identity is important and decreases with experienced difficulty if difficulty is understood as meaning that the identity is impossible to attain (Oyserman, 2007, 2009a; Oyserman et al., 2006).

Sometimes working on one's healthy self-goals - getting in shape, dieting, refraining from late nights, or starting to exercise-feels easy, but often this is not the case. Even imagining oneself doing what it takes - setting an earlier alarm, carrying a bag lunch rather than getting a burger and fries with friends-can 
feel difficult. How are these metacognitive experiences - the feeling of ease or difficulty accompanying thinking about one's health identities - to be interpreted? IBM theory predicts that either ease or difficulty can motivate sustained action depending on the lay theory of what ease or difficulty means that is brought to mind. Consider difficulty. If working on one's health goals is experienced as hard, does this mean that the goal is important ("no pain, no gain"), or does it mean that the goal is impossible to attain for people like oneself? IBM theory predicts that both interpretations of difficulty are possible and which comes to mind depends on which identity comes to mind and what it means in context. We began this article with a summary of the health disparities literature which convincingly shows that low-income and minority group members are likely to experience lack of control, unfair treatment, and contexts in which others like themselves also find healthy choices difficult. Therefore, we predict that unless provided an alternate interpretation, low-income and minority individuals will be likely to interpret difficulties in attaining healthy self-goals as meaning that these goals are impossible for people like themselves.

Two studies test this prediction with low-income minority children (Smith et al., 2014). Low-income minority fourth- to eighth-grade students enrolled in a remedial after-school program were randomly assigned to one of two conditions. Their participation in the remedial program was acknowledged either with no further interpretation of their school difficulties or with the interpretation that they were enrolled in the remedial program because "school is important." Being provided this interpretation of difficulty mattered. Students provided the "school is important" interpretation of difficulty generated more school-focused identities when asked what they would be like in the coming year and they performed better at a novel math task.

Moreover, providing low-income minority children an interpretation of difficulty as meaning that succeeding was impossible for them was no worse than providing no interpretation at all, as demonstrated in a follow-up study. In this experiment, seventh- and eighth-grade low-income minority students were randomly assigned to one of three conditions. Students randomly assigned to the experimental groups were subtly provided an interpretation of their difficulty; those randomly assigned to the control group were not. They cued interpretation of difficulty by having experimental groups respond to a biased scale about schoolwork. Half responded to items reflecting the idea that when schoolwork is hard it means ones' efforts are best spent elsewhere. Half responded to items reflecting the idea that when schoolwork is hard it means that the task is important. All children were then given an increasingly difficult task. As task items became more difficult to solve, children performed worse unless they were subtly provided with an interpretation of difficulty as importance (Smith et al., 2014, Study 2).

While these studies do not target health identities, we (Smith \& Oyserman, 2012) have begun to test these predictions in the health domain. In one experiment, 
college students were randomly assigned to one of four conditions. In two conditions, students were primed to consider an interpretation of difficulty as meaning that health is an important self-goal. In the other two conditions, students were primed to consider an interpretation of difficulty as meaning that health is an impossible-to-attain self-goal. Students were asked either how frequently it happens that they find it better to spend their effort elsewhere when they face difficulty in physical activity tasks or how frequently it happens that they find it important to keep trying when they face difficult physical activity tasks. Students were either led to believe that their experience (of physical activity as important or impossible) was more frequent or less frequent than others (following Schwarz, 1996). Feeling that one experiences difficulty as impossibility more often than one's peers should imply that physical activity is "not for me." Feeling that one experiences difficulty as importance more often than one's peers should imply that physical activity is "for me." The reverse should happen if one experiences difficulty as impossibility less often than one's peers (that should imply that physical activity is "for me") or if one experiences difficulty as importance less often than one's peers (that should imply that physical activity is "not for me").

That is what we found. Students in the importance conditions (more common for self than for others that physical activity is important, less common for self than for others that time is better spent elsewhere) were more likely to report plans to engage in physical activity for the coming week than students in the impossibility conditions. Physical exertion is less likely if context cues the sense that it is common for me to feel that my efforts are better spent on something else and uncommon for me to feel that difficulty just underscores how important physical activity is.

\section{Implications for Public Health Policy}

IBM theory is rooted in the assumption that identities matter because they provide a basis for meaning making and for action (Oyserman, in press; Oyserman et al., 2011; Oyserman \& Markus, 1998). This implies first, that people are motivated to act in identity-congruent ways, and second, that when a behavior feels identity-congruent in context, it feels natural, and difficulty in engaging in the behavior is likely to be interpreted as meaning that it is important (e.g., "no pain, no gain") (Oyserman, 2007). Moreover, it also implies that the reverse is the case for behaviors that do not feel identity-congruent in context. These behaviors do not feel natural, and difficulty in engaging in them is likely to be interpreted as meaning that the behavior is not identity-congruent (e.g., "dieting is for women, not men like me") or lead to questioning the identity itself (e.g., "maybe I am never going to be a thin person"). While identities feel stable they are highly malleable and context sensitive. People are unlikely to be aware of the impact of situations on their identities. 
Identities matter for health, but not because health is solely due to individual choices. Research on health disparities and unfair treatment highlights the importance of considering health as more than an individual choice. From a policy perspective, the question is not whether improving health outcomes would be a good outcome. Obviously, it would be. Rather the policy question is whether Americans are willing to change the social structural factors that result in health disparities. If Americans are not willing to engage in redistributive policies then social stratification is likely to remain. This social stratification means that racial and ethnic minorities, poor and low-income individuals and those with few assets have little power or control over their work and neighborhood contexts. Policies that either reduce stratification or at least increase sense of personal control are likely to improve health outcomes by reducing both fatalistic attitudes toward engaging in healthy behaviors and reducing the belief that health is a middle class pursuit beyond the grasp of people like oneself. By increasing sense of control, reducing health fatalism, and increasing identity-congruence of healthy behaviors, these policies would alleviate some of the chronic stressors that can contribute to negative health outcomes (see Jackson et al, 2010).

Structural change may be an unpalatable policy goal for economic conservatives as it would require willingness to intervene to reduce stratification and improve socioeconomic outcomes. Even if palatable from a values perspective, these changes would be relatively impossible to make without policies to implement large-scale, long-term, and financially intensive interventions. However, as noted next, this does not mean that health disparities cannot be addressed from a policy perspective.

Consider that experiences of financial insecurity, lack of control, unfair treatment, and discrimination are themselves damaging in part because each of these experiences highlights that what one does has little impact on one's outcomes. When these experiences are distributed along race, socioeconomic status, and other stratifying factors, they also contribute to a sense of common fate with relevant social groups. Interventions addressing these experiences are relevant for policies designed to increase engagement with health and health care even if structural change itself is not possible. Small interventions can matter if they influence people's perceptions of what is possible for them and people like themselves in the future (Oyserman, 2007, 2009a, b). Lack of attention to IBM may explain why traditional exercise and abstinence regimes are unattractive, even though health-risk behaviors are common and people are aware that lifestyle choices matter (Fine et al., 2004).

As demonstrated in the experimental literature we reviewed, the same identity can be made to feel health-relevant or health-irrelevant (or even unhealthy) depending on how it is cued in context. We suggest policy initiatives should acknowledge that choosing healthy behaviors is more likely if it feels congruent with important current social identities (like race-ethnicity and social class) 
or possible future identities (like becoming a better parent). Moreover, actions need to be seen as identity-congruent (people like me can take the stairs instead of the elevator), and difficulties along the way need to be framed as highlighting the importance, not the impossibility of the healthy goal in order to reduce health disparities. Initiatives such as workplace efforts to engage in healthy practices by linking work identity to healthy choices are common for higher earning professional and salaried workers but would equally benefit hourly workers.

Outside the workplace, the elements of IBM can still be leveraged. A first step is to make the "face" of programs and policies seem relevant to people like oneself. In the United States, this race-matching approach is relatively common. For example, initiatives focusing on African Americans create group-specific materials on a range of health topics including smoking (Robinson et al., 2003), heart health (U.S. DHHS, 2008a), and exercise (U.S. DHHS, 2008b). However, race-match is not enough because what it means to be a member of one's racialethnic group as it relates to health must also be cued. Each of the above-cited programs explicitly attempts to make the link between African American identity and health strategies. The heart health program offers suggestions to integrate healthier eating into social gatherings so that healthy eating fits with valuing family and community connections while the exercise initiative suggests ways for young African American women to be active while maintaining one's appearance and style. To succeed, programs must create an identity-congruent interpretation of difficulty in working on health goals. The smoking initiative program cited above tackles this issue. First, potential quitters are informed that quitting smoking is even more difficult for African Americans. Next, they are explicitly provided an interpretation of difficulty as goal importance and a sign that progress is being made.

\section{Concluding Remarks}

We began by noting that healthy choices are not easy to make, but that it is implausible that ill health is simply an individual-level effect of poor choices since health and ill-health are unequally distributed across social groups, not only in the United States but worldwide. Social stratification does not directly cause individual behavior but does highlight the need to consider how health disparities emerge and what can be done about them. We used IBM as a theoretical framework to illuminate the macro-micro interaction. IBM predicts that people often end up making unhealthy choices even when they desire to be healthy, and that social stratification influences health, in part by influencing what people see as possible for themselves and people like them. In this way, social stratification both exacerbates the universal tendency to use social identities as meaning-making lenses and structures what the meaning is likely to be in ways that undermine health for some and promote it for others. 


\section{References}

Adler, N. E., \& Rehkopf, D. H. (2008). U.S. disparities in health: Descriptions, causes, and mechanisms. Annual Review of Public Health, 29, 235-252.

Ahluwalia, J. S., Harris, K. J., Catley, D., Okuyemi, K. S., \& Mayo, M. S. (2002). Sustained-release bupropion for smoking cessation in African Americans: A randomized controlled trial. Journal of the American Medical Association, 2888, 468-474.

Alegría, M., Pescosolido, B. A., Williams, S., \& Canino, G. (2011). Culture, race/ethnicity and disparities: Fleshing out the socio-cultural framework for health services disparities. In B. A. Pescosolido, J. K. Martin, J. D. McLeod, \& A. Rogers (Eds.), Handbook of the sociology of health, illness, and healing (pp. 363-382). New York: Springer.

American Public Health Association (2010). A majority of Americans are making healthy lifestyle changes. Retrieved August 1, 2011, from http://www.apha.org/about/ news/pressreleases/2010/nphwrelease.htm.

Amos, A., Currie, C., Gray, D., \& Elton, R. (1998). Perceptions of fashion images from youth magazines: Does a cigarette make a difference? Health Education Research, 13, 491-501.

Amos, A., Gray, D., Currie, C., \& Elton, R. (1997). Healthy or druggy? Self-image, ideal image and smoking behaviour among young people. Social Science \& Medicine, 45, 847-858.

Associated Press (2011). We say we like salads, but we order burgers. Retrieved October 10, 2011, from http://www.nola.com/health/index.ssf/2011/10/salads_are_nice_but_burgers_ar.html.

August, K. J., \& Sorkin, D. H. (2010). Racial/ethnic disparities in exercise and dietary behaviors of middle-aged and older adults. Journal of General Internal Medicine, 26, 245-250.

Banks, J., Marmot, M., Oldfield, Z., \& Smith, J. (2006). Disease and disadvantage in the United States and England, Journal of the American Medical Association, 295, 2037-2045.

Berger, J., \& Rand, L. (2008). Shifting signals to help health: Using identity signaling to reduce risky health behaviors. Journal of Consumer Research, 35, 509-518.

Bird, S., \& Bogart, L. (2001). Perceived race-based and socioeconomic status (SES)-based discrimination in interactions with health care providers. Ethnicity \& Disease, 11, 554-563.

Bowen, D. J., Christensen, C. L., Powers, D., Graves, D. R., \& Anderson, C. A. M. (1998). Effects of counseling and ethnic identity on perceived risk and cancer worry in African American women. Journal of Clinical Psychology in Medical Settings, 5, 365-379.

Bowen, D., Hickman, K., \& Powers, D. (1997). Importance of psychological variables in understanding risk perceptions and breast cancer screening of African American women. Women's Health: Research on Gender, Behavior and Policy, 3, 227-242.

Brownell, K., Kersh, R., Ludwig, D., Post, R., Puhl, R., Schwartz, M., \& Willett, W. (2010). Personal responsibility and obesity: A constructive approach to a controversial issue. Health Affairs, 29, 379-387.

Burgard, S. A., Brand, J. E., \& House, J. E. (2009). Perceived job insecurity and worker health in the United States. Social Science \& Medicine, 69, 777-785.

Choudhry, U. K. (1992). Health promotion among immigrant women from India living in Canada. Journal of Nursing Scholarship, 30, 269-274.

Christakis, N. A., \& Fowler, J. H. (2007). The spread of obesity in a large social network over 32 years. The New England Journal of Medicine, 357, 370-379.

Christakis, N. A., \& Fowler, J. H. (2008). The collective dynamics of smoking in a large social network. The New England Journal of Medicine, 358, 2249-2258.

Cooper, L., Hill, M., \& Powe, N. (2002). Designing and evaluating interventions to eliminate racial and ethnic disparities in health care. Journal of General Internal Medicine, 17, 477-486.

Croghan, R., Griffin, C., Hunter, J., \& Phoenix, A. (2006). Style failure: Consumption, identity and social exclusion. Journal of Youth Studies, 9, 463-478.

Fine, L., Philogene, G., Gramling, R., Coups, E., \& Sinha, S. (2004). Prevalence of multiple chronic disease risk factors: 2011 National Health Interview Survey. American Journal of Preventative Medicine, 27, 18-24.

Gallop (2010). Six in 10 overweight or obese in U.S., more in '09 than in '08. Retrieved August 1, 2011, from http://www.gallup.com/poll/125741/six-overweight-obese.aspx. 
Gibbons, F., \& Gerrard, M. (1995). Predicting young adults' health risk behavior. Journal of Personality and Social Psychology, 69, 505-517.

Gibbons, F., \& Gerrard, M. (1997). Health images and their effects on health behavior. In B. Buunk \& F. Gibbons (Eds.), Health, coping, and well-being: Perspectives from social comparison theory (pp. 63-94). Mahwah, NJ: Erlbaum.

Gibbons, F., Gerrard, M., Blanton, H., \& Russell, D. (1998). Reasoned action and social reaction: Willingness and interaction as independent predictors of health risk. Journal of Personality and Social Psychology, 74, 1164-1180.

Glanz, K., Rimer, B. K., \& Viswanath, K. (Eds.) (2008). Health behavior and health education: Theory, research, and practice (4th ed.). San Francisco, CA: Jossey-Bass.

Gray, D., Amos, A., \& Currie, C. (1997). Decoding the image - consumption, young people, magazines, and smoking. An exploration of theoretical and methodological issues. Health Education Research, 12, 505-517.

Guendelman, M., Cheryan, S., \& Monin, B. (2011). Fitting in but getting fat: Identity threat and dietary choices among U.S. immigrant groups. Psychological Science, 22, 959-967.

Helweg-Larsen, M., \& Collins, B. (1997). A social psychological perspective on the role of knowledge about AIDS in AIDS prevention. Current Directions in Psychological Science, 6, 23-26.

House, J., Landis, K., \& Umberson, D. (1988). Social relationships and health. Science, 241, 540545 .

Irmak, C., Vallen, B., \& Robinson, S. (2011). The impact of food names on dieters' and non-dieters' food evaluations and consumption. Journal of Consumer Research, 38, 390-405.

Jackson, J., Knight, K., \& Rafferty, J. (2010). Race and unhealthy behaviors: Chronic stress, the HPA axis, and physical and mental health disparities over the life course. American Journal of Public Health, 100, 933-939.

Knecht, S., Reinholz, J., \& Kenning, P. (2007). 'The spread of obesity in a social network': Comment. The New England Journal of Medicine, 357, 1866-1867.

Krause, N., Shaw, B., \& Liang, J. (2011). Social relationships in religious institutions and healthy lifestyles. Health Education \& Behavior, 38, 25-38.

Lantz, P., House, J., Lepkowski, J., Williams, D., Mero, R., \& Chen, J. (1998). Socioeconomic factors, health behaviors, and mortality. Journal of the American Medical Association, 279, 1703-1708.

Link, B., Phelan, J., Miech, R., \& Westin, E. (2008). The resources that matter: Fundamental social causes of health disparities and the challenge of intelligence. Journal of Health and Social Behavior, 49, 72-91.

Lynch, J. W., Smith, G. D, Kaplan, G. A., \& House, J. S. (2000). Income inequality and mortality: Importance to health of individual income, psychosocial environment, or material conditions. British Medical Journal, 320, 1200-1204.

Marmot, M. (2001). Inequalities in health. New England Journal of Medicine, 345, 134-136.

Martin, K. A., \& Leary, M. R. (2001). Single, physically active, female: The effects of information about exercise participation and body weight on perceptions of young women. Social Behavior and Personality, 16, 1-12.

McFerran, B., Dahl, D. W., Fitzsimons, G. J., \& Morales, A. C. (2009). I'll have what she's having: Effects of social influence and body type on the food choices of others. Journal of Consumer Research, 36, 915-929.

McFerran, B., Dahl, D. W., Fitzsimons, G. J., \& Morales, A. C. (2010). Might an overweight waitress make you eat more? How the body type of others is sufficient to alter our food consumption. Journal of Consumer Psychology, 20, 146-151.

Oyserman, D. (2007). Social identity and self-regulation. In A. W. Kruglanski \& E. T. Higgins (Eds.), Social psychology: Handbook of basic principles (pp. 432-453). New York: Guilford.

Oyserman, D. (2008). Possible selves: Identity-based motivation and school success. In H. Marsh, R. Craven, \& D. McInerney (Eds.), Self-processes, learning and enabling human potential dynamic new approaches (Vol. 3, pp. 269-288). USA: Information Age Press.

Oyserman, D. (2009a). Identity-based motivation: Implications for action-readiness, proceduralreadiness, and consumer behavior. Journal of Consumer Psychology, 19, 250-260. 
Oyserman, D. (2009b). Identity-based motivation and consumer behavior. Response to commentary. Journal of Consumer Psychology, 19, 276-279.

Oyserman, D. (2011). Culture as situated cognition: Cultural mindsets, cultural fluency, and meaning making. European Review of Social Psychology, 22, 164-214.

Oyserman, D. (in press). Identity-based motivation. In R. Scott (Editor-in-Chief), Emerging trends in the behavioral and social sciences. Wiley Press.

Oyserman, D., Brickman, D., Bybee, D., \& Celious, A. (2006). Fitting in matters: Markers of in-group belonging and academic outcomes. Psychological Science, 17, 854-861.

Oyserman, D., Bybee, D. \& Terry, K. (2006). Possible selves and academic outcomes: How and when possible selves impel action. Journal of Personality and Social Psychology, 91, 188204.

Oyserman, D., \& Destin, M. (2010). Identity-based motivation: Implications for intervention. The Counseling Psychologist, 38, 1001-1043.

Oyserman, D., Elmore, K., \& Smith, G. (2012). Self, self-concept, and identity. In M. Leary \& J. Tangney (Eds.), Handbook of self and identity (2nd ed., pp. 69-104). New York: Guilford.

Oyserman, D., Fryberg, S. A., \& Yoder, N. (2012). Identity-based motivation and health. Journal of Personality and Social Psychology, 93, 1011-1027.

Oyserman, D., \& Lee, S. W. S. (2008). Does culture influence what and how we think? Effects of priming individualism and collectivism. Psychological Bulletin, 134, 311-342.

Oyserman, D., \& Markus, H. R. (1998). Self as social representation. In U. Flick (Ed.), The psychology of the social (pp. 107-125). New York: Cambridge.

Penner, L. A., Dovidio, J. F., Edmondson, D., Dailey, R. K., Markova, T., Albrecht, T. L., \& Gaertner, S. L. (2009). The experience of discrimination and black-white health disparities in medical care. Journal of Black Psychology, 35, 180-203.

Robinson, R., Sutton, C., James, D., \& Orleans, C. (2003). Pathways to freedom: Winning the fight against tobacco. Washington, D.C.: DHHS, Center for Disease Control and Prevention.

Royce, J., Hymowitz, N., Corbett, K., Hartwell, T., \& Orlandi, M. (1993). Smoking cessation factors among African Americans and Whites. American Journal of Public Health, 83, 220-226.

Ruhm, C. J. (2005). Healthy living in hard times. Journal of Health Economics, 24, 341-363.

Schnittker, J., \& McLeod, J. D. (2005). The social psychology of health disparities. Annual Review of Sociology, 31, 75-104.

Schuldt, J. P., \& Schwarz, N. (2010). The "organic" path to obesity? Organic claims influence calorie judgments and exercise recommendations. Judgment and Decision Making, 5, 144-150.

Schwarz, N. (1996). Cognition and communication: Judgmental biases, research methods, and the logic of conversation. Hillsdale, NJ: Erlbaum.

Schwarz, N., Bless, H., Strack, F., Klumpp, G., Rittenauer-Schatka, H., \& Simons, A. (1991). Ease of retrieval as information: Another look at the availability heuristic. Journal of Personality and Social Psychology, 61, 195-202.

Smith, G. C., Novin, S. F., Elmore, K., \& Oyserman, D. (2014). From school difficulty to school possibility: Identity-based motivation and interpretation of difficulty in succeeding. Paper under review.

Smith, G. C., \& Oyserman, D. (2012). Health and difficulty. Unpublished data.

Smith, J. A., \& Robertson, S. (2008). Men's health promotion: A new frontier in Australia and the UK? Health Promotion International, 23, 283-289.

Stead, M., McDermott, L., MacKintosh, A., \& Adamson, A. (2011). Why healthy eating is bad for young people's health: Identity, belonging and food. Social Science \& Medicine, 72, 11311139.

Tamburlini, G., \& Cattaneo, A. (2007). The spread of obesity in a social network. The New England Journal of Medicine, 357, 1866.

Tarrant, M., \& Butler, K. (2011). Effects of self-categorization on orientation towards health. British Journal of Social Psychology, 50, 121-139.

U.S. Department of Health and Human Services, National Heart Lung and Blood Institute. (2008a). On the move to better heart health for African Americans. (NIH Publication No. 08-5829). Retrieved December 11, 2011, from http://www.nhlbi.nih.gov/health/public/heart/other/chdblack/aariskfactors.pdf 
U.S. Department of Health and Human Services, National Institute of Diabetes and Digestive and Kidney Diseases. (2008b). Celebrate the Beauty of Youth. (NIH Publication No. 08-4903). Retrieved December 11, 2011, from http://win.niddk.nih.gov/publications/celebrate.htm

Uskul, A., Keller, J., \& Oyserman, D. (2008). Regulatory fit and health behavior. Psychology \& Health, $23,327-346$.

Werch, C. (2007). The behavior-image model: A paradigm for integrating prevention and health promotion in brief interventions. Health Education Research, 22, 667-690.

Werch, C., Moore, M., Bian, H., DiClemente, C., Huang, I-C, Ames, S., Thombs, D., Weiler, R., \& Pokorny, S. (2008). Efficacy of a brief image-based multiple-behavior intervention for college students. Annals of Behavioral Medicine, 36, 149-157.

Werch, C., Moore, M., Diclemente, C., Owen, D., Carlson, J., \& Jobli, E. (2005). Single vs. multiple drug prevention: Is more always better? A pilot study. Substance Use \& Misuse, 40, 1085-1101.

Williams, D. R., \& Jackson, P. (2005). Social sources of racial disparities in health. Health Affairs, 24, 325-334.

Williams, D. R., John, D., Oyserman, D., Sonnega, J., Mohammed, S., \& Jackson, J. (2012). Unresolved measurement issues in research on discrimination and health: An exploratory study. American Journal of Public Health, 102, 975-978.

Ybarra, V., Sanchez, G., \& Medeiros, J. (2011). The missing link in the social determinants literature: The impact of political factors on health status and health disparities in the US. Paper presented at American Political Science Association Annual Meeting, Seattle, WA.

DAPHNA OYSERMAN (http://sitemaker.umich.edu/daphna.oyserman) is a Dean's Professor of Psychology, Professor of Education and of Communication at the University of Southern California. She was previously a professor at the University of Michigan, a Fellow at the Center for Advanced Studies in the Behavioral Sciences, received the Humboldt Scientific Contribution Prize of the German Alexander von Humboldt Foundation, and was a W.T. Grant Faculty Scholar Award. Her research examines how small changes in context can shift mindsets, and so, the perceived meaning of behaviors and situations, with large downstream effects on important and consequential outcomes, including health and academic performance. She conducts experimental work to test her theoretical conceptualization of the underlying processes and translate insights from this work into real-world interventions. One line of work focuses on cultural differences in affect, behavior, and cognition - how people feel, act, and think about themselves and the world around them. A related second line of work focuses on racial, ethnic, and social class gaps in school achievement and health. Throughout, she examines how apparently "fixed" differences between groups may in fact mask highly malleable situated processes that can be profoundly influenced through small interventions that shift mindset.

GEORGE C. SMITH is a doctoral candidate in the Social Psychology Department at the University of Michigan. His research deals with issues of identity and academic motivation, specifically, how different framings of identity can be motivating or demotivating for students in school. He is also interested in the impact of role models and the messages they send about the likelihood of different academic outcomes. More recently, he has been doing work on the metacognitive 
experience of difficulty and how it can foster both disengagement and increased effort by students in school.

KRISTEN ELMORE is a doctoral candidate in the Joint Doctoral Program in Social Work and Social Psychology at the University of Michigan. Her research interests include school-based preventive interventions, academic motivation, and health and achievement gaps related to socioeconomic status, race, and gender. Currently, her research focuses on the paths through which contextual factors shape individuals' social identities and possible selves with the goal of understanding how these factors can be directed to encourage students' achievement success and individual's health behaviors. 